\title{
Anti-Inflammatory and Immunostimulatory Effects of Extract from Culture of Effective Microorganisms (ECEM) Revealed by Functional Genomics and Metabolome Analyses
}

\author{
Masaki Shintani' ${ }^{1}$, Fusako Mitsunaga ${ }^{2,3}$, Shun Shimabukuro1, Shin Nakamura ${ }^{2,3^{*}}$ \\ ${ }^{1}$ EM Research Organization Inc., Kitanakagusuku, Japan \\ ${ }^{2}$ Intelligence and Technology Lab Inc., Kaizu, Japan \\ ${ }^{3}$ Biomedical Institute, NPO Primate Agora, Inuyama, Japan \\ Email: snakamura@itechlab.co.jp
}

Received 13 August 2015; accepted 27 August 2015; published 17 September 2015

Copyright (C) 2015 by authors and Scientific Research Publishing Inc.

This work is licensed under the Creative Commons Attribution International License (CC BY).

http://creativecommons.org/licenses/by/4.0/

(c) (i) Open Access

\begin{abstract}
The extract from culture of effective microorganisms (ECEM) is a secondary metabolite produced in symbiotic culture of a mixture of yeasts and lactic bacteria followed by photosynthetic bacteria. Metabolomics studies have demonstrated that ECEM contained several active ingredients associated with anti-inflammation through interactions with nuclear factor- $\kappa B$. Functional genomics using DNA microarrays revealed that ECEM had distinctive anti-inflammatory and immunostimulatory actions in RAW264.7 cells. ECEM inhibited the LPS-upregulated expression of one group of pro-inflammatory genes (iNos, Il6 and Cox2) but not another group genes (Tnf, Ccl7 and Dusp2); it also upregulated the expression of $C d 1 d 1$, which participates in antigen presentation on lipids, resulting in activation of natural killer $T$ (NKT) cells related to infection defense and cancer. Bacterial glycosylated lipid and other related complex lipids in ECEM are thought to trigger this upregulation of $C d 1 d 1$ expression. These results suggest that ECEM functions in the immune response in both inflammation and antigen presentation and that it contains components important for these functions. These novel effects of ECEM could be invaluable for developing functional drinks or health beverages.
\end{abstract}

\section{Keywords}

DNA Microarray, Secondary Metabolites, iNos, Il6, Cd1d1

\footnotetext{
${ }^{*}$ Corresponding author.

How to cite this paper: Shintani, M., Mitsunaga, F., Shimabukuro, S. and Nakamura, S. (2015) Anti-Inflammatory and Immunostimulatory Effects of Extract from Culture of Effective Microorganisms (ECEM) Revealed by Functional Genomics and Metabolome Analyses. Food and Nutrition Sciences, 6, 1115-1125. http://dx.doi.org/10.4236/fns.2015.612116
} 


\section{Introduction}

Extract from culture of effective microorganisms (ECEM) is a secondary metabolite produced by the symbiosis culture of 5 microorganisms: 2 strains of yeasts (Saccharomyces cerevisiae and Candida ethanolica), 2 strains of lactic acid bacteria (Lactobacillus casei and Lactobacillus farraginis), and photosynthetic bacteria (Rhodopseudomonas palustris). The secondary metabolites from a few microorganisms are known to contain invaluable effective compounds, not only for developing drugs to treat cancer or infectious diseases [1]-[3], but also for exploiting functional food and/or drink for health control. Establishing the health claims of ECEM as functional drink requires in-depth analysis because the components and functions of the symbiosis culture metabolite are very complicated and difficult to identify. Functional genomics studies using DNA microarrays are powerful tools for elucidating the biological effects of functional foods and/or drinks containing complex components produced by microorganism culture [4] [5]. Metabolome analysis provides high-throughput information regarding the chemical nature of low-molecular weight compounds contained in the complicated secondary metabolites [6] [7].

The first stage of studying the biological effects of newly developed foods or drinks should be performed on an in vitro cellular level rather than that in vivo in animals because of the well-controlled conditions and welldefined results. RAW264.7 cells, a murine macrophage cell line with the potential for antigen presentation, are widely used for in vitro first-stage studies examining the biological effects of functional food and/or drink for health control, as murine model are commonly used in vivo for second-stage studies [8]-[10].

In the current study, we examined the in vitro anti-inflammatory and immunostimulatory functions of ECEM in RAW264.7 cells using genome informatics of DNA microarray analysis. We also identified anti-inflammatory components in ECEM through bioinformatics analysis of metabolome data. Our results demonstrate that ECEM has remarkable health effects for modulating inflammation and immune responses and can be included in functional drinks.

\section{Materials and Methods}

\subsection{Preparation of the Symbiosis Culture Product, "ECEM"}

Two strains of Lactobacillus (L. casei and L. farraginis), two strains of yeast (S. cerevisiae and C. ethanolica), and photosynthetic bacteria (R. palustris) were kind gift from Dr. Teruo Higa (director of the International EM Technology Research Center, Meio University). The first step of symbiosis culture, which included $L$. casei, $L$. farragini, S. cerevisiae, and C. ethanolica, was performed in medium containing $7 \%(\mathrm{v} / \mathrm{v})$ sugarcane molasses for 4 weeks at $30^{\circ} \mathrm{C}$ until the solution reached $\mathrm{pH} 3.5$ or less, followed by the addition of new sugarcane molasses medium for an additional $2-4$ weeks at $30^{\circ} \mathrm{C}$; culture was terminated when the $\mathrm{pH}$ was 3.5 or less. The obtained symbiosis culture product was adjusted to $\mathrm{pH} 6.5$ - 7.5 by adding natural calcium powder. This mixture was used for second-step culture that included $R$. palustris, which was previously grown in medium containing $0.5 \%(\mathrm{v} / \mathrm{v})$ yeast extract. The second step of symbiosis culture was carried out in medium composed of the original symbiosis culture product, the $R$. palustris culture product, and water at $\mathrm{pH} 7.0-9.0$ for 3 months at $25^{\circ} \mathrm{C}$. The supernatant of the second symbiosis culture product was transferred to another container, followed by maturation for 7 days at $25^{\circ} \mathrm{C}$ to obtain final secondary metabolites. The resulting symbiosis culture product was filtered through a 50-nm filter and referred to as ECEM, which was used for subsequent experiments.

\subsection{Lipopolysaccharide (LPS) Assay}

The LPS assay was conducted using an Endospecy ES-50 M Set (Seikagaku Corporation, Tokyo, Japan).

\subsection{Cell Culture and ECEM Treatment}

Mouse macrophage like cell line, RAW264.7 cells (Summit Pharmaceuticals International Corporation, Osaka, Japan), was cultured with RPMI 1640 medium containing $10 \%$ fetal calf serum in $5 \% \mathrm{CO}_{2}$ at $37^{\circ} \mathrm{C}$. To examine the in vitro function of ECEM, the cells were incubated with the culture medium containing the indicated concentrations of ECEM or LPS from Escherichia coli O55 (Wako Pure Chemical Industries, Ltd., Osaka, Japan) for $24 \mathrm{~h}$. 


\subsection{Cell Viability Assay}

A colorimetric assay for cell viability was performed using a WST-1 reagent Kit (Takara Bio Inc., Shiga, Japan). Cells were incubated with the culture medium for 24 at $37^{\circ} \mathrm{C}$ and $5 \% \mathrm{CO}_{2}$ followed by addition of $10 \mu \mathrm{L}$ of the WST-1 reagent. After incubation for $4 \mathrm{~h}$ at $37^{\circ} \mathrm{C}$ and $5 \% \mathrm{CO}_{2}$, absorbance at $450 \mathrm{~nm}$ was measured using Bio-Rad Microplate Reader (iMark 168 - 1130 JA; Bio-Rad Laboratories, Inc., Hercules, CA, USA). Cell culture examinations were performed under the conditions for cell viability with more than $80 \%$.

\subsection{Metabolome Analysis}

For metabolome analysis, $10 \mathrm{~mL}$ ECEM was concentrated by lyophilization followed by rehydration in $1 \mathrm{~mL}$ water. The concentrated ECEM was centrifuged at $15,000 \mathrm{rpm}$ for $1 \mathrm{~min}$ at $25^{\circ} \mathrm{C}$ to remove water-insoluble material(s) and then filtered with 10-K cut-off membrane. The obtained water-soluble and low-molecular weight fraction of ECEM was subjected to metabolome analysis. Metabolome analysis was performed using an LCTOF-MS system with a combination of Waters LCT Premier XE/ACQUITY UPLC and ACQUITY UPLC HSS T3 column using an elution solvent with a liner gradient of $0.1 \%$ formic acid and acetonitrile. From the detected peak signal, the corresponding chemical formula, molecular mass, and/or compound name were deduced using a data mining system of metaATOne (mata Profiling and meta Compareing).

\subsection{RNA Preparations and RIN Analysis}

RNA preparation was performed as described previously [11]. Briefly, total RNA was extracted from the harvested RAW264.7 cells using Isogen (NipponGene Co., Ltd., Tokyo, Japan). Aqueous phase samples were DNase-treated using the RNase-Free DNase Set (QIAGEN, Inc., Hilden, Germany). The extracted RNA was further purified using an RNeasy MinElute Cleanup Kit (QIAGEN), and RNA quantity and purity were evaluated photometrically at $260 \mathrm{~nm}, 280 \mathrm{~nm}$, and $320 \mathrm{~nm}$ using an Ultrospec 2000 (GE Healthcare Bio-Sciences AB, Little Chalfont, UK). RNA quality was assessed using an Agilent 2100 Bioanalyzer (Agilent Technologies, Inc., Santa Clara, CA, USA) and RNA Integrity Number (RIN) was calculated. RNA samples with RIN above 7 were used for gene expression analyses using DNA microarray and real-time reverse transcription (RT)-PCR.

\subsection{DNA Microarray Analysis}

Total RNA (200 ng) from the RAW 264.7 cells was used to generate cDNA and Cy3-labeled cRNA with a Low Input Quick-Amp Labeling Kit (Agilent Technologies, Inc., Santa Clara) according to the manufacturer's instructions. The labeled cRNA was photometrically examined to determine the quantity and dye-incorporation ratio with an Ultrospec 2000, and it was hybridized to a Mouse Gene Expression $4 \times 44 \mathrm{~K}$ v2 Microarray (Agilent Technologies, Inc.). The array was scanned with GenePix 6000B (Molecular Devices, LLC, Sunnyvale), and the obtained image was processed with GenePix Pro 6.0 Software (Molecular Devices, LLC). The features were manually examined, and spots of poor quality were flagged and filtered out.

The signal data for the features (spots of array) were then imported into GeneSpring 12.6 (Agilent Technologies), and further analyses were performed using the software. The signal data from the arrays were normalized using the 75th percentile method [12], and baseline transformation was performed with the median of the control samples. Quality control was performed in order to filter out signal data with standard errors over 0.2.

To analyze the differentially expressed genes, the fold change vs. the control samples was calculated, and genes with a fold change greater than 2.0 or less than 0.5 were extracted for the ECEM-treated groups. Gene ontology analysis of the selected genes was performed using GeneSpring 12.6 software, and gene sets with a corrected $\mathrm{p}$ value $<0.1$ were considered significant.

\subsection{Real Time Reverse Transcription-Polymerase Chain Reaction (RT-PCR)}

We performed quantitative RT-PCR to confirm the DNA microarray results for the following genes: nitric oxide synthase 2, inducible (iNos/Nos2); interleukin 6 (Il6); tumor necrosis factor (Tnf); CD1d1 antigen (Cd1d1); ATP-binding cassette, sub-family B (MDR/TAP), member 9 (Abcb9); methyltransferase like 1 (Mettl1); WD repeat domain 4 (Wdr4); tRNA methyltransferase 61A (Trmt61a); protein arginine N-methyltransferase 7 (Prmt7); tumor necrosis factor, alpha-induced protein 3 (Tnfaip3); transferrin receptor (Tfrc); leucine rich repeat 
protein 1 (Lrr1 (Ppil5)); BCL2/adenovirus E1B interacting protein 3 (Bnip3); mitochondrial ribosomal protein L15 (Mrpl15), and histidine ammonia lyase ( $\mathrm{Hal}$ ). cDNA was synthesized from the isolated total RNA with PrimeScript Reverse Transcriptase (Takara Bio Inc., Shiga, Japan) with RNase Inhibitor (Takara Bio), dNTP Mixture (Takara Bio), and Oligo dT Primer (Takara Bio). Real-time PCR was performed using an Mx3000P QPCR System (Agilent Technologies) with a SYBR Premix Ex Taq kit (Takara Bio) with specific primers for each gene. In each run, a standard curve was generated by a serially diluted known GAPDH amplicon, as described previously [11], to calculate the cDNA copy number of the genes. The quantity of the mRNA of interest was expressed as its ratio against that of a suitable reference gene, low-density lipoprotein receptor-related protein 10 (Lrp10) [13]. Primer sequences (F: forward 5' to 3', R: reverse 5' to 3') are available upon request.

\section{Results}

\subsection{LPS Assay}

ECEM contained $11.3 \mathrm{ng} / \mathrm{mL}$ LPS. This appeared to be derived from the gram-negative photosynthetic bacteria (R. palustris).

\subsection{Metabolome Analysis}

Metabolome analysis using the LC-TOF-MS system provided useful information regarding the effective components in ECEM. There were 84 major ingredient peaks with intensities higher than 1000 in the water-soluble and low-molecular weight fractions of ECEM. Thirty-four peaks of the 84 major peaks were assigned as known compounds. The biological functions of these known compounds were deduced through bioinformatics analysis using PubMed and other biomedical databases. Table 1 shows the compounds found in the ECEM and their biological roles associated with estrogen receptor (16-alpha-hydroxyestrone), anti-inflammation (embelin, gingerol, and diallyl sulfide), and antimicrobials or antibiotics (4-amino-4-deoxychorismate and phytuberin).

\subsection{Functional Genomics}

Since ECEM contained LPS, gene expression events occurred in RAW cells during incubation with ECEM, which were thought to have resulted from three factors: LPS-mediated alteration in gene expression, ECEM-alleviation to the LPS-mediated alteration, or ECEM-specific and LPS-independent gene expression. We conducted functional genomics analysis using DNA microarray for the RAW cell lysate; cells were obtained by culture for $24 \mathrm{~h}$ with medium alone (control), $10 \mathrm{ng} / \mathrm{mL} \mathrm{LPS}$, and 10\% ECEM. This enabled identification of the possible functions of ECEM related to genomic event(s) in ECEM-treated RAW cells; these included 1) alleviative or 2) no alleviative effect on LPS-mediated alteration in gene expression and/or 3) LPS-independent upregulation or downregulation in gene expression.

The expression of 108 genes was upregulated by LPS and mitigated by ECEM. Among these, some genes-Table 2 shows examples-including iNos (Nos2), Il6, Ccrl2, Nfkbiz, Csf1, C3, Il1f9, Ccl5, Cox2 (Ptgs2), Saa1, Il1b, Cxcl2, Il1f6, Irg1, and Saa3, participate in inflammation. Interestingly, ECEM appeared to inhibit LPS-upregulated expression of these genes because of markedly negative fold change of ECEM/LPS, suggesting the anti-inflammatory function of ECEM. Figure 1 shows that ECEM inhibited LPS-upregulated expression of iNos (Figure 1(a)) and Il6 (Figure 1(b)) in RAW cells stimulated by $10 \mathrm{ng} / \mathrm{ml}$ LPS, respectively.

Table 1. Major ingredients found in the ECEM and their biological roles ingredients.

\begin{tabular}{|c|c|c|}
\hline Compound ${ }^{*}$ & Function & References \\
\hline 4-Amino-4-deoxychorismate & Intermediate for antimicrobial drug & [14] [15] \\
\hline Embelin $^{* *}$ & NF- $\kappa$ B inhibition, anti-inflammation & {$[16]-[18]$} \\
\hline Gingerol $^{* *}$ & iNOS down regulation, $\mathrm{NF}-\kappa \mathrm{B}$ inactivation, anti-inflammation & {$[9][19]$} \\
\hline Phytuberin & $\begin{array}{c}\text { Phytoalexin (antimicrobial compounds for plant), microRNA } \\
\text { regulation for cancer treatment }\end{array}$ & {$[20][21]$} \\
\hline Diallyl sulfide ${ }^{* *}$ & Inhibitory action to NO production, & {$[22][23]$} \\
\hline 16 alpha-Hydroxyestrone ${ }^{* *}$ & Interaction with ER (Estrogen receptor) & [24] \\
\hline
\end{tabular}

* In order of peak intensity. ${ }^{* *}$ Ingredients associating with anti-inflammation, NF- $\kappa$ B inhibition, NO production, or ER interaction. 
Table 2. Genes up regulated by LPS and alleviation by ECEM to their LPS-up regulated expression. Gene set categorized as “Inflammatory response and/or immunoresponse” by Gene Ontology. Typical 25 genes.

\begin{tabular}{|c|c|c|c|c|}
\hline \multirow{2}{*}{$\begin{array}{l}\text { Gene } \\
\text { Symbol }\end{array}$} & \multirow{2}{*}{ Gene Name } & \multicolumn{3}{|c|}{ Fold Change } \\
\hline & & LPS/Cnt & ECEM/Cnt & ECEM/LPS ${ }^{*}$ \\
\hline Il6 & Interleukin 6 & 217.6 & 7.5 & -29.0 \\
\hline Saa3 & Serum amyloid A 3 & 997.1 & 40.0 & -24.9 \\
\hline Saa1 & Serum amyloid A 1 & 40.9 & 2.3 & -17.7 \\
\hline iNos & Nitric oxide synthase 2, inducible (Nos2) & 7.1 & -2.5 & -17.4 \\
\hline Ccl5 & Chemokine (C-C motif) ligand 5 & 27.8 & 2.0 & -14.2 \\
\hline$I l 1 b$ & Interleukin 1 beta & 39.4 & 3.6 & -10.9 \\
\hline $\operatorname{Irg} 1$ & Immune responsive gene 1 & 31.9 & 4.6 & -7.0 \\
\hline $\operatorname{Cox} 2$ & Cyclooxigenase 2 (prostaglandin-endoperoxide synthase 2) & 13.0 & 2.2 & -5.9 \\
\hline Il1f9 & Interleukin 1 family & 8.6 & 1.5 & -5.9 \\
\hline Nfkbiz & $\begin{array}{l}\text { Nuclear factor of kappa light polypeptide gene } \\
\text { Enhancer in B-cells inhibitor }\end{array}$ & 3.4 & -1.7 & -5.8 \\
\hline Cxcl2 & Chemokine (C-X-C motif) ligand 2 & 19.1 & 4.3 & -4.4 \\
\hline Csf 1 & Colony stimulating factor 1 (macrophage) & 3.0 & -1.2 & -3.7 \\
\hline Ccrl2 & Chemokine (C-C motif) receptor-like 2 & 2.1 & -1.7 & -3.6 \\
\hline $\operatorname{Tnfs} f 15$ & Tumor necrosis factor (ligand) superfamily, member 15 & 2.2 & -1.5 & -3.4 \\
\hline Oasl1 & 2'-5' oligoadenylate synthetase-like 1 & 8.2 & 2.5 & -3.3 \\
\hline$I l 1 f 6$ & Interleukin 1 family & 15.1 & 4.9 & -3.1 \\
\hline$C d 274$ & CD274 antigen & 2.2 & -1.4 & -3.0 \\
\hline$M \times 1$ & Myxovirus (influenza virus) resistance 1 & 8.1 & 2.8 & -2.9 \\
\hline Isg15 & ISG15 ubiquitin-like modifier & 6.8 & 2.3 & -2.9 \\
\hline Gbp2 & Guanylate binding protein 2 & 2.1 & -1.3 & -2.8 \\
\hline$M \times 2$ & Myxovirus (influenza virus) resistance 2 & 3.1 & 1.2 & -2.6 \\
\hline C3 & Complement component 3 & 2.1 & -1.1 & -2.3 \\
\hline$Z b p 1$ & Z-DNA binding protein 1 & 7.2 & 3.1 & -2.3 \\
\hline Ifit1 & Interferon-induced protein with tetratricopeptide repeats 1 & 3.9 & 1.7 & -2.3 \\
\hline
\end{tabular}

*Negative fold change meaning inhibitory fold of ECEM to LPS-mediated up regulation. Genes highlighted in bold type were mentioned in discussion.

However, no mitigating effect of ECEM was observed on LPS-upregulated expression of some inflammatory genes, including Tnf, Ccl7, and Dusp 2 (Table 3). As shown in Figure 1(c), ECEM displayed little inhibitory effect on LPS-mediated upregulation of Tnf expression. This indicates that ECEM had different effects on LPSmediated altered expression of inflammatory genes, by inhibiting iNos, Il6, and related genes, but no inhibitory effect on $T n f$ and related genes.

Table 4 shows two genes, $C d 1 d 1$ and $A b c b 9$, which were upregulated specifically by ECEM but not LPS. These genes are known to be associated with antigen presentation in the immune response. Cd1d1 recognizes lipid antigens and activates NKT. This suggests that ECEM contains simple and/or complex lipid compound(s) from the cell wall of both bacteria and yeast. Little upregulation of Cd1d1 was observed in RAW cells stimulated with $10 \mathrm{ng} / \mathrm{mL}$ LPS though LPS was aglycosylated lipid and had lipid-A moiety.

As shown in Table 5, five genes, Bnip3, Ddit4, Ero1l, Hipk2, and Ier3, were downregulated specifically by ECEM but not LPS. These genes were categorized as apoptosis-related by ontology analysis using Gene Spring, suggesting a regulatory effect of ECEM on apoptosis. 
Table 3. Genes up regulated by LPS and no alleviation by ECEM to LPS-up regulated their expression. Gene set categorized as “Inflammation/Immune response” by Gene Ontology. Typical 6 genes.

\begin{tabular}{cccc}
\hline \multirow{2}{*}{ Gene Symbol } & Gene Name & \multicolumn{2}{c}{ Fold Change } \\
\cline { 2 - 4 } Tnf & Tumor necrosis factor & LPS/Cnt & ECEM/Cnt \\
Ccl7 & Chemokine (C-C motif) ligand 7 & 6.2 & 6.3 \\
Ccl2 & Chemokine (C-C motif) ligand 2 & 5.1 & 5.7 \\
Dusp2 & Dual specificity phosphatase 2 & 4.9 & 5.1 \\
Pou2f2 & POU domain, class 2, transcription factor 2 & 5.5 & 4.7 \\
Cxcl10 & Chemokine (C-X-C motif) ligand 10 & 4.6 & 4.6 \\
\hline
\end{tabular}

Genes highlighted in bold type were mentioned in discussion.

Table 4. Genes up regulated specifically by ECEM but not LPS. Gene set categorized as “Antigen presentation” by Gene Ontology. Typical 2 genes.

\begin{tabular}{ccc}
\hline \multirow{2}{*}{ Gene Symbol } & Gene Name & Fold Change \\
\cline { 3 - 3 } Cd1d1 & CD1d1 antigen & ECEM/Cnt \\
Abcb9 & ATP-binding cassette, sub-family B (MDR/TAP), member 9 & 4.4 \\
\hline
\end{tabular}

Table 5. Genes downregulated specifically by ECEM but not LPS. Gene set categorized as "Intrinsic apoptosis” by Gene Ontology. Typical 5 genes.

\begin{tabular}{ccc}
\hline \multirow{2}{*}{ Gene Symbol } & Gene Name & Fold Change \\
\cline { 2 - 3 } Bnip3 & BCL2/adenovirus E1B interacting protein 3, nuclear gene encoding mitochondrial protein & ECEM/Cnt \\
Ddit4 & DNA-damage-inducible transcript 4 & -7.7 \\
Ero1l & ERO1-like (S. cerevisiae) & -5.0 \\
Hipk2 & Homeodomain interacting protein kinase 2 & -3.5 \\
Ier3 & Immediate early response 3 & -3.3 \\
\hline
\end{tabular}

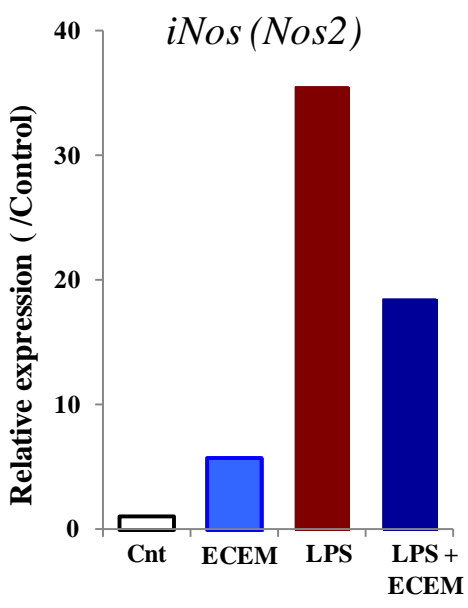

(a)

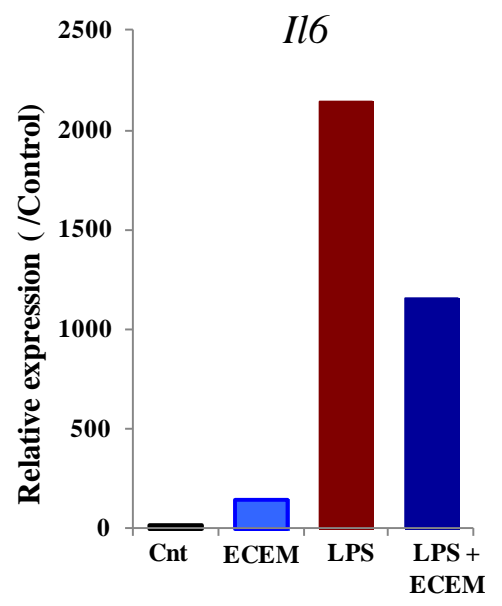

(b)

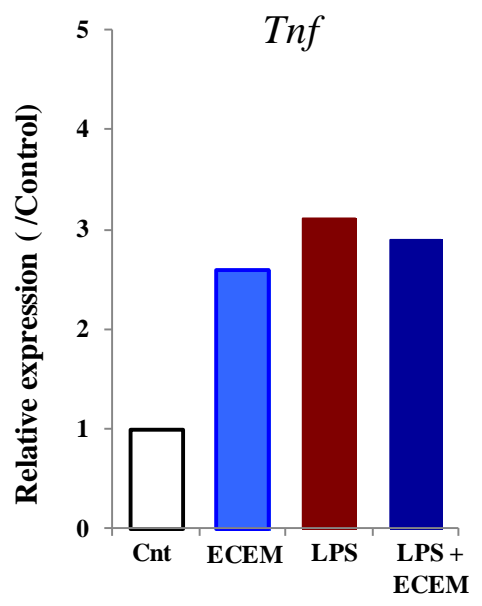

(c)

Figure 1. Inhibitory effect of ECEM on LPS-upregulated expression of genes, iNos and Il6 but not Tnf, in RAW cells. RAW cells were incubated with medium (Cnt), 10\% ECEM (final concentration, ECEM), $10 \mathrm{ng} / \mathrm{ml}$ LPS (final concentration, LPS), or $10 \mathrm{ng} / \mathrm{ml}$ LPS and 10\% ECEM (LPS + ECEM) followed by subjected to real time RT-PCR for gene expression analyses. (a) iNos; (b) Il6; and (c) Tnf. 


\section{Discussion}

ECEM is a secondary metabolite produced in symbiosis culture with 5 microorganisms, including 2 strains of yeasts, 2 strains of lactic acid bacteria, and photosynthetic bacteria. Symbiosis culture involves co-cultivation of 2 or more different microorganisms. Symbiosis culture mimics some ecological situations where microorganisms co-exist within complex microbial communities. This mixed culture leads to significantly enhanced production of constitutively present compounds and/or to accumulation of cryptic compounds that are not detected in axenic cultures [25] Symbiosis culture can result in increased yields of previously undetected metabolites and, importantly, the induction of previously unexpressed pathways for bioactive constituents [6] [26]. These secondary induced products that are yielded through co-cultivation of mixed microorganisms are known to be valuable natural metabolites [1]. Numerous secondary metabolites are defense compounds for plant that protect against biotic and abiotic stresses such as infection, predation, ultraviolet radiation, and drought [2]. Other secondary metabolites act as regulatory molecules and exhibit powerful bioactive properties in animals, including humans, by acting as antioxidants, anti-inflammatory, and immune-enhancing agents, as well as antimicrobials [3]. In humans, some microorganisms also synthesize their own secondary metabolites that regulate patho-physiological functions such as inflammation and immune responses [27].

Because of the complexity of secondary metabolites, advanced and high-throughput analytical methods (e.g., metabolomics and functional genomics) are important for identifying effective constituents and the biological functions of these metabolites. In the current study, we conducted both metabolomics analysis, using LC-TOFMS, and functional genomics analysis, using DNA microarray, to investigate the constituent-function relationship of ECEM. We employed a murine macrophage cell line, RAW264.7 cells, for in vitro study because RAWcells are widely used to investigate the biological effect of natural products, including secondary metabolites [8] and we have a plan to perform second stage in vivo study using mouse model.

LPS is a potent mediator in gram negative bacteria and elicits inflammatory and/or immune responses by altering the expression of genes, including iNos, Il6, and Tnf, which are associated with these responses [28]. Previous studies have examined upregulated expression of these pro-inflammatory genes in LPS-stimulated RAW 264.7 cells [29]. Since ECEM contained $11.3 \mathrm{ng} / \mathrm{mL}$ LPS, one can consider two events may have occurred: a synergistic or no effect by ECEM on LPS action upon co-culture of RAW cells with ECEM or LPS. Interestingly, however, DNA microarray showed that ECEM inhibited LPS-upregulated expression of genes, including iNos and Il6, which are related to the inflammatory response (Table 2). The inhibitory effect of ECEM was confirmed by co-culture of RAW cells with both ECEM and LPS (Figure 1(a) and Figure 1(b)). Unexpectedly, ECEM exhibited little inhibitory action on LPS-upregulated expression of some pro-inflammatory genes, including Tnf (Table 3 and Figure 1(c)). This characteristic finding suggests that ECEM has anti-inflammatory action through selective suppression of transcriptional events of a gene group of iNos and Il6, and but not another group of Tnf.

Metabolome analysis revealed that ECEM contained anti-inflammatory compounds, including embelin, gingerol, diallyl sulfide, and 16-alpha-hydroxyestrone (Table 1). It is well-known that the LPS-elicited inflammatory response is initiated by binding of TLR4 with LPS on the cell surface, followed by activation of intracellular machinery, particularly the nuclear factor (NF)- $\kappa$ B signaling system [8]. Embelin is a plant benzoquinone derivative with antitumor and anti-inflammation effects [16] and was reported to inhibit NF- $\kappa \mathrm{B}$ activation [17]. Gingerol, the main pungent component of ginger used in traditional Chinese medicine, is known to have antiinflammatory properties. Gingerol inhibited NF- $\kappa$ B-mediated iNos expression and enzyme activity in macrophage-like cells, RAW264.7, by decreasing LPS-induced I $\kappa \mathrm{B}$-alpha degradation, resulting in reduced NF- $\kappa \mathrm{B}$ activity [9]. Diallyl disulfide (DAS) is a major sulfur compound in garlic and has anti-inflammatory effect [30]. DAS suppressed iNos expression and nitric oxide production in LPS-stimulated RAW264.7 cells [31]. 16-Alpha-hydroxyestrone has estrogen-like properties and binds or interacts with the estrogen receptor (ER) [24], which regulates transcription factors by inhibiting NF- $\kappa \mathrm{B}$ activity on several levels [32]. ER was known to suppressIl6 expression through interaction with $\mathrm{NF}-\kappa \mathrm{B}$ [33]. In a previous report of $17 \beta$-estradiol (E(2)-like Tan IIA), its inhibitory effect on expression of iNos and Il6 was observed in LPS-induced RAW264.7 cells in an ER-dependent manner [34]. The estrogenic flavonoid, baicalein, also exerted an anti-inflammatory effect by inhibiting iNos and Cox2 mRNA expression in LPS-stimulated RAW264.7 cells through an ER-dependent pathway and through regulation of NF- $\kappa$ B activation [10]. Thus, ECEM appears to regulate the inflammatory response by downregulating pro-inflammatory genes, including iNos, Il6, and Cox2. 
Tnf is also a pro-inflammatory gene upregulated by activation of NF- $\kappa$ B signaling with LPS and other stimuli [35] [36]. Interestingly, ECEM exhibited no inhibitory effect on upregulation of Tnf expression in LPS-stimulated RAW cells, whereas ECEM potently suppressed the upregulated expression of iNos, Il6, and Cox2. There have been a few reports regarding differential regulation of Tnf and Il6 expression: mRNA expression of Tnf and Il6 were regulated differently in LPS-stimulated macrophages under hyperthermia conditions [37]; The DASsuppressed nitric oxide production was independent of TNF in LPS-stimulated RAW264.7 cell [22]; Methanol extracts from Euphorbia cooperi significantly reduced the production of nitric oxide and IL-6, but not TNF, in LPS-stimulated RAW264.7 macrophages and reporter assays demonstrated reduced activator protein- 1 activity, while NF- $\kappa$ B activity was not reduced [38]. LPS-induced genes were divided into 2 groups, an activating transcription factor 3-independent group including Tnf and Il1 and an activating transcription factor 3-dependent group including iNos and Il6, by regulation with heat shock transcription factor 1 under high-temperature stress conditions [39]. These data suggest that transcriptional events of pro-inflammatory cytokines are complicated and regulated by association with not only NF- $\kappa \mathrm{B}$ but also other factor(s). Moreover, the Tnf and iNos groups are regulated by different manner in LPS-mediated upregulated expression of these pro-inflammatory cytokine genes. Thus, ECEM affected inhibition of LPS-upregulated gene expression of one group, including iNos, Il6, and Cox2, but did not affect expression of another group containing Tnf, Ccl7, and Dusp 2, although the detailed mechanism of differential regulation of ECEM remains unclear. ECEM appears to be a good reagent for investigating differential regulation mechanisms on gene expression of iNos and Tnf groups in LPS-stimulated cells.

Another characteristic function of ECEM was observed in upregulated gene expression of $C d 1 d 1$ and $A b c b 9$, which participate in antigen presentation. $C d 1 d 1$ is a member of gene family specific to rodents, mice, and rats, and a homologue to human $C D 1 D$. $C D 1 D$ is a non-classical major histocompatibility complex molecule and presents lipid antigens to natural killer T (NKT) cells. NKT cells can produce both Th1 and Th2 cytokines and have immunostimulatory action against infectious diseases, as well as against cancer [40]. In the current study, little upregulation of Cd1d1 expression was observed in LPS-stimulated RAW cells. This likely caused LPS to indirectly upregulate CD1 expression through glycolipid autoantigen synthesis [41]. An insufficient amount of LPS, at a final concentration of $10 \mathrm{ng} / \mathrm{mL}$, was used in our cell culture experiments, as $1 \mathrm{mg} / \mathrm{mL}$ LPS was reported to be optimal for upregulating Cd1d1 expression in LPS-treated RAW264.7 cells [42]. These results demonstrated that upregulation of Cd1d1 expression is a characteristic function of lipid components but not contaminating LPS in ECEM. Another effect elicited by ECEM on the immune response was upregulation of $A b c b 9$ expression. ABCB9 is also known as transporter associated with antigen processing-like, and translocates peptides from the cytosol into the lumen of lysosomes, indicating its involvement in antigen presentation in macrophages [43]. Since ABC transporters, including the ABCB subfamily, are known to function in lipid translocation [44], $A b c b 9$ likely has a synergic effect on $C d 1 d 1$-mediated lipid antigen presentation in macrophages. Thus, ECEM has unique immunomodulatory action to stimulate lipid antigen presentation by upregulating expression of both $C d 1 d 1$ and $A b c b 9$.

\section{Conclusion}

In conclusion, we identified effective components in and biological functions of ECEM, a secondary metabolite produced by symbiotic culture with lactic bacteria and yeasts followed by photosynthetic bacteria, using metabolomic and functional genomic analyses. ECEM revealed unique anti-inflammatory functions to suppress LPSupregulated gene expression of one group of pro-inflammatory genes (iNos, Il6, and Cox2) but not of another group of genes (Tnf, Ccl7, and Dusp2). ECEM also showed characteristic immunostimulatory effects, upregulating the expression of $C d 1 d 1$ associated with antigen presentation on lipids and resulting in activation of NKT cells. These effects make ECEM a suitable material for developing a functional drink and/or food for health control.

\section{Acknowledgements}

We appreciate the assistance of Dr. Teruo Higa, director of the International EM Technology Research Center, Meio University, for his support during this study. We also thank to Mr. Yamashita, Intelligence and Technology Lab Inc., for providing technical assistance.

\section{References}

[1] Williams, D.H., Stone, M.J., Hauck, P.R. and Rahman, S.K. (1989) Why Are Secondary Metabolites (Natural Products) 
Biosynthesized? Journal of Natural Products, 52, 1189-1208. http://dx.doi.org/10.1021/np50066a001

[2] Pichersky, E. and Gang, D.R. (2000) Genetics and Biochemistry of Secondary Metabolites in Plants: An Evolutionary Perspective. Trends in Plant Science, 5, 439-445. http://dx.doi.org/10.1016/S1360-1385(00)01741-6

[3] Siddiqui, M.S., Thodey, K., Trenchard, I. and Smolke, C.D. (2012) Advancing Secondary Metabolite Biosynthesis in Yeast with Synthetic Biology Tools. FEMS Yeast Research, 12, 144-170. http://dx.doi.org/10.1111/j.1567-1364.2011.00774.x

[4] Chae, S.W., Mitsunaga, F., Jung, S.J., Ha, K.-C., Sin, H.S., Jang, S.H. and Nakamura, S. (2014) Nutrigenomic Study on Immunomodulatory Function of Cordyceps Mycelium Extract (Paecilomyces hepiali) in Mitomycin C-Treated Mice. Food and Nutrition Sciences, 5, 2217-2224. http://dx.doi.org/10.4236/fns.2014.522235

[5] Chae, S.W., Mitsunaga, F., Jung, S.J., Ha, K.-C., Sin, H.S., Jang, S.H. and Nakamura, S. (2015) Mechanisms Underlying the Antifatigue Effects of the Mycelium Extract of Cordyceps (Paecilomyces hepiali, CBG-CS-2) in Mice in the Forced Swimming Test. Food and Nutrition Sciences, 6, 287-298. http://dx.doi.org/10.4236/fns.2015.62029

[6] Bertrand, S., Bohni, N., Schnee, S., Schumpp, O., Gindro, K. and Wolfender, J.L. (2014) Metabolite Induction via Microorganism Co-Culture: A Potential Way to Enhance Chemical Diversity for Drug Discovery. Biotechnology Advances, 32, 1180-1204. http://dx.doi.org/10.1016/j.biotechadv.2014.03.001

[7] Krug, D. and Müller, R. (2014) Secondary Metabolomics: The Impact of Mass Spectrometry-Based Approaches on the Discovery and Characterization of Microbial Natural Products. Natural Product Reports, 31, 768-783. http://dx.doi.org/10.1039/c3np70127a

[8] Frazier-Jessen, M.R., Thompson, C.D., Brown, R., Rawat, R., Nordan, R.P. and Feldman, G.M. (2002) NF-kappaB Rlements Vontribute to JunB Inducibility by Lipopolysaccharide in the Murine Macrophage Cell Line RAW264.7. FEBS Letters, 513, 203-207. http://dx.doi.org/10.1016/S0014-5793(02)02295-0

[9] Aktan, F., Henness, S., Tran, V.H., Duke, C.C., Roufogalis, B.D. and Ammit, A.J. (2006) Gingerol Metabolite and a Synthetic Analogue Capsarol Inhibit Macrophage NF-kappaB-mediated iNOS Gene Expression and Enzyme Activity. Planta Medica, 72, 727-734. http://dx.doi.org/10.1055/s-2006-931588

[10] Fan, G.W., Zhang, Y., Jiang, X., Zhu, Y., Wang, B., Su, L., et al. (2013) Anti-Inflammatory Activity of Baicalein in LPS-Stimulated RAW264.7 Macrophages via Estrogen Receptor and NF- $\kappa$ B-Dependent Pathways. Inflammation, 36, 1584-1591. http://dx.doi.org/10.1007/s10753-013-9703-2

[11] Jeong, A.R., Nakamura, S. and Mitsunaga, F. (2008) Gene Expression Profile of Th1 and Th2 Cytokines and Their Receptors in Human and Nonhuman Primates. Journal of Medical Primatology, 37, 290-296. http://dx.doi.org/10.1111/j.1600-0684.2008.00289.x

[12] Shippy, R., Fulmer-Smentek, S., Jensen, R.V., Jones, W.D., Wolber, P.K., Johnson, C.D., et al. (2006) Using RNA Dample Titrations to Assess Microarray Platform Performance and Normalization Techniques. Nature Biotechnology, 24, 1123-1131. http://dx.doi.org/10.1038/nbt1241

[13] Gabrielsson, B.G., Olofsson, L.E., Sjögren, A., Jernås, M., Elander, A., Lönn, M., et al. (2005) Evaluation of Reference Genes for Studies of Gene Expression in Human Adipose Tissue. Obesity Research, 13, 649-652. http://dx.doi.org/10.1038/oby.2005.72

[14] Kerbarh, O., Bulloch, E.M., Payne, R.J., Sahr, T., Rébeillé, F. and Abell, C. (2005) Mechanistic and Inhibition Studies of Chorismate-Utilizing Enzymes. Biochemical Society Transactions, 33, 763-766. http://dx.doi.org/10.1042/BST0330763

[15] Zhang, Y., Bai, L. and Deng, Z. (2009) Functional Characterization of the First Two Actinomycete 4-Amino-4Deoxychorismate Lyase Genes. Microbiology, 155, 2450-2459. http://dx.doi.org/10.1099/mic.0.026336-0

[16] Chitra, M., Sukumar, E., Suja, V. and Devi, C.S. (1994) Antitumor, Anti-Inflammatory and Analgesic Property of Embelin, a Plant Product. Chemotherapy, 40, 109-113. http://dx.doi.org/10.1159/000239181

[17] Ahn, K.S., Sethi, G. and Aggarwa, B.B. (2007) Embelin, an Inhibitor of X Chromosome-Linked Inhibitor-of-Apoptosis Protein, Blocks Nuclear Factor- $\kappa$ B (NF- $\kappa$ B) Signaling Pathway Leading to Suppression of NF- $\kappa$ B-Regulated Antiapoptotic and Metastatic Gene Products. Molecular Pharmacology, 71, 209-219. http://dx.doi.org/10.1124/mol.106.028787

[18] Schaible, A.M., Traber, H., Temml, V., Noha, S.M., Filosa, R., Peduto, A., et al. (2013) Potent Inhibition of Human 5-Lipoxygenase and Microsomal Prostaglandin $\mathrm{E}_{2}$ Synthase-1 by the Anti-Carcinogenic and Anti-Inflammatory Agent Embelin. Biochemical Pharmacology, 86, 476-486. http://dx.doi.org/10.1111/j.1750-3841.2009.01308.X

[19] Pan, M.H., Hsieh, M.C., Hsu, P.C., Ho, S.Y., Lai, C.S., Wu, H., et al. (2008) 6-Shogaol Suppressed Lipopolysaccharide-Induced Up-Expression of iNOS and COX-2 in Murine Macrophages. Molecular Nutrition and Food Research, 52, 1467-1477. http://dx.doi.org/10.1002/mnfr.200700515

[20] Komaraiah, P., Reddy, G.V., Reddy, P.S., Raghavendra, A.S., Ramakrishna, S.V. and Reddanna, P. (2003) Enhanced Production of Antimicrobial Sesquiterpenes and Lipoxygenase Metabolites in Elicitor-Treated Hairy Root Cultures of 
Solanum tuberosum. Biotechnology Letters, 25, 593-597. http://dx.doi.org/10.1023/A:1023038804556

[21] Tilghman, S.L., Rhodes, L.V., Bratton, M.R., Carriere, P., Preyan, L.C., Boue, S.M., et al. (2013) Phytoalexins, miRNAs and Breast Cancer: A Review of Phytochemical-Mediated miRNA Regulation in Breast Cancer. Journal of Health Care for the Poor and Underserved, 24, 36-46. http://dx.doi.org/10.1353/hpu.2013.0036

[22] Chang, H.P., Huang, S.Y. and Chen, Y.H. (2005) Modulation of Cytokine Secretion by Garlic Oil Derivatives Is Associated with Suppressed Nitric Oxide Production in Stimulated Macrophages. Journal of Agricultural and Food Chemistry, 53, 2530-2534. http://dx.doi.org/10.1021/jf048601n

[23] Lee, H.S., Lee, C.H., Tsai, H.C. and Salter, D.M. (2009) Inhibition of Cyclooxygenase 2 Expression by Diallyl Sulfide on Joint Inflammation Induced by Urate Crystal and IL-1beta. Osteoarthritis and Cartilage, 17, 91-99. http://dx.doi.org/10.1016/j.joca.2008.05.010

[24] Zhu, B.T., Han, G.Z., Shim, J.Y., Wen, Y. and Jiang, X.R. (2006) Quantitative Structure-Activity Relationship of Various Endogenous Estrogen Metabolites for Human Estrogen Receptor Alpha and Beta Subtypes: Insights into the Structural Determinants Favoring a Differential Subtype Binding. Endocrinology, 147, 4132-4150. http://dx.doi.org/10.1210/en.2006-0113

[25] Marmann, A., Aly, A.H., Lin, W., Wang, B. and Proksch, P. (2014) Co-Cultivation-A Powerful Emerging Tool for Enhancing the Chemical Diversity of Microorganisms. Marine Drugs, 12, 1043-1065. http://dx.doi.org/10.3390/md12021043

[26] Pettit, R.K. (2009) Mixed Fermentation for Natural Product Drug Discovery. Applied Microbiology and Biotechnology, 83, 19-25. http://dx.doi.org/10.1007/s00253-009-1916-9

[27] Verbeke, K.A., Boobis, A.R., Chiodini, A., Edwards, C.A., Franck, A., Kleerebezem, M., et al. (2015) Towards Microbial Fermentation Metabolites as Markers for Health Benefits of Prebiotics. Nutrition Research Reviews, 28, 42-66. http://dx.doi.org/10.1017/S0954422415000037

[28] Paludan, S.R. (2000) Synergistic Action of Pro-Inflammatory Agents: Cellular and Molecular Aspects. Journal of Leukocyte Biology, 67, 18-25.

[29] Park, J.S., Lee, E.J., Lee, J.C., Kim, W.K. and Kim, H.S. (2007) Anti-Inflammatory Effects of Short Chain Fatty Acids in IFN-Gamma-Stimulated RAW 264.7 Murine Macrophage Cells: Involvement of NF-kappaB and ERK Signaling Pathways. International Immunopharmacology, 7, 70-77. http://dx.doi.org/10.1016/j.intimp.2006.08.015

[30] Hashizume, Y., Shirato, K., Abe, I., Kobayashi, A., Mitsuhashi, R., Shiono, C., et al. (2012) Diallyl Disulfide Reduced Dose-Dependently the Number of Lymphocyte Subsets and Monocytes in Rats. Journal of Nutritional Science and Vitaminology (Tokyo), 58, 292-296. http://dx.doi.org/10.3177/jnsv.58.292

[31] Chang, H.P. and Chen, Y.H. (2005) Differential Effects of Organosulfur Compounds from Garlic Oil on Nitric Oxide and Prostaglandin E2 in Stimulated Macrophages. Nutrition, 21, 530-536. http://dx.doi.org/10.1016/j.nut.2004.07.018

[32] Kalaitzidis, D. and Gilmore, T.D. (2005) Transcription Factor Cross-Talk: The Estrogen Receptor and NF-kappaB. Trends in Endocrinology and Metabolism, 16, 46-52. http://dx.doi.org/10.1016/j.tem.2005.01.004

[33] Liu, H., Liu, K. and Bodenner, D.L. (2005) Estrogen Receptor Inhibits Interleukin-6 Gene Expression by Disruption of Nuclear Factor kappaB Transactivation. Cytokine, 31, 251-257. http://dx.doi.org/10.1016/j.cyto.2004.12.008

[34] Fan, G.W., Gao, X.M., Wang, H., Zhu, Y., Zhang, J., Hu, L.M., et al. (2009) The Anti-Inflammatory Activities of Tanshinone IIA, an Active Component of TCM, Are Mediated by Estrogen Receptor Activation and Inhibition of iNOS. The Journal of Steroid Biochemistry and Molecular Biology, 113, 275-280. http://dx.doi.org/10.1016/j.jsbmb.2009.01.011

[35] Müller, J.M., Ziegler-Heitbrock, H.W. and Baeuerle, P.A. (1993) Nuclear Factor kappa B, a Mediator of Lipopolysaccharide Effects. Immunobiology, 187, 233-256. http://dx.doi.org/10.1016/S0171-2985(11)80342-6

[36] Smahi, A., Courtois, G., Rabia, S.H., Döffinger, R., Bodemer, C., Munnich, A., et al. (2002) The NF-kappaB Signalling Pathway in Human Diseases: From Incontinentia Pigmenti to Ectodermal Dysplasias and Immune-Deficiency Syndromes. Human Molecular Genetics, 11, 2371-2375. http://dx.doi.org/10.1093/hmg/11.20.2371

[37] Ensor, J.E., Wiener, S.M., McCrea, K.A., Viscardi, R.M., Crawford, E.K. and Hasday, J.D. (1994) Differential Effects of Hyperthermia on Macrophage Interleukin-6 and Tumor Necrosis Factor-Alpha Expression. American Journal of Physiology, 266, C967-C974.

[38] Cho, Y.C., Lee, I.S., Seo, H., Ju, A., Youn. D., Kim, Y., et al. (2014) Methanol Extracts of Euphorbia cooperi Inhibit the Production of Inflammatory Mediators by Inhibiting the Activation of c-Jun N-Terminal Kinase and p38 in Murine Macrophages. Molecular Medicine Reports, 10, 2663-2668. http://dx.doi.org/ 10.3892/mmr.2014.2560

[39] Takii, R., Inouye, S., Fujimoto, M., Nakamura, T., Shinkawa, T., Prakasam, R., et al. (2010) Heat Shock Transcription Factor 1 Inhibits Expression of IL-6 through Activating Transcription Factor 3. Journal of Immunology, 184, 10411048. http://dx.doi.org/10.4049/jimmunol.0902579

[40] Brutkiewicz, R.R., Lin, Y., Cho, S., Hwang, Y.K., Sriram, V. and Roberts, T.J. (2003) CD1d-Mediated Antigen Pres- 
entation to Natural Killer T (NKT) Cells. Critical Reviews in Immunology, 23, 403-419. http://dx.doi.org/10.1615/CritRevImmunol.v23.i56.30

[41] Kronenberg, M. and Kinjo, Y. (2005) Infection, Autoimmunity, and Glycolipids: T Cells Detect Microbes through Self-Recognition. Immunity, 22, 657-659. http://dx.doi.org/10.1016/j.immuni.2005.06.001

[42] Saxena, R.K., Vallyathan. V. and Lewis, D.M. (2003) Evidence for Llipopolysaccharide-Induced Differentiation of RAW264.7 Murine Macrophage Cell Line into Dendritic like Cells. Journal of Biosciences, 28, 129-134. http://dx.doi.org/10.1007/BF02970143

[43] Zhao, C., Haase, W., Tampé, R. and Abele, R. (2008) Peptide Specificity and Lipid Activation of the Lysosomal Transport Complex ABCB9 (TAPL). The Journal of Biological Chemistry, 283, 17083-17091. http://dx.doi.org/10.1074/jbc.M801794200

[44] Coleman, J.A., Quazi, F. and Molday, R.S. (2013) Mammalian P4-ATPases and ABC Transporters and Their Role in Phospholipid Transport. Biochimica et Biophysica Acta, 1831, 555-574. http://dx.doi.org/10.1016/j.bbalip.2012.10.006 